\title{
The Dark Side of Social Media (Review)
}

Salo, J., Mäntymäki, M. and Islam, A.K.M.N. (eds) (2018) 'The Dark Side of Social Media' [Special Issue], Internet Research, 28(5).

\section{NICHOLAS FURZE, Canterbury Christ Church University}

As its title suggests, the articles that make up the contents of this special collection are not focused upon the various ways in which new media has enriched people's lives. Instead, this special issue seeks to interrogate a wide variety of potential risks and problems that social media presents, whether that be on the national level, as occurs with Brett G. Johnson's analysis into managing and tolerating extreme speech on social media, or even on the personal level as occurs with Laura Francis Bright and Kelty's Logan's research into the effects of advertising and social media fatigue on both consumers and brands.

As such a broad range of articles would imply, and indeed as was stated by the special issue's editors in the introduction, the findings that occur across the course of these eight articles reveal that the various negatives that can occur in social media exist within a broad spectrum. This ranges from larger issues that are widely publicised through various news organisations to smaller, more mundane stories, that whilst not as widely known, can still result in negative experiences for the social media consumer.

In When social media traumatises teens: the roles of online risk exposure, coping and posttraumatic stress, the authors have utilised a web-based diary methodology in order to examine the impact of negative online risk experiences on adolescents. Their aim was to ascertain the extent that negative online risk experiences cause post-traumatic stress disorder (PTSD) symptoms in adolescents. The authors' research has revealed that explicit content and exposure to cyberbullying and sexual solicitations do indeed evoke the symptoms of PTSD. However, the research also indicated that teens took active measures to cope with the online risks soon after they felt threatened. This can help to enhance their resilience and these coping measures can help reduce long-term negative effects. The authors then argue that if these coping measures can be detected, the social media platforms could possibly embed interventions into their framework to support these coping processes. Such interventions include teaching teenagers how to report abusive online behaviours to the authorities, instead of teaching them to disengage from social media altogether.

As a result of the various research practices employed in this special issue, Jari Salo, Matti Mäntymäki, and A.K.M Najmul Islam, the editors of this collection, present an 
argument that there are three areas of social media research which would benefit from increased focus in the future. Firstly, that there is a need for research on how social media functions within a workplace context (Mäntymäki and Riemer, 2016), particularly as various forms of social media are now prolific in many workplaces. Secondly, they argue that there is currently a gap in the understanding of how the various characteristics of social media platforms may help contribute to negative consequences for the individual. Thirdly, they argue that in order to account for the potential social desirability bias (Fisher, 1993) that relates to people's own negative social media actions (e.g. cyberbullying and trolling), future research would benefit from utilising a greater variety of research designs considering data from multiple sources.

Overall, this edited collection presents a wide variety of exciting research into social media, and presents a welcome addition into this rapidly growing field of research. All of these articles present an original contribution to the field, whilst also provoking questions which would benefit from being developed further as the various problems and concerns that social media raises for the individual and for wider society are identified and understood. Everyone with an interest in this field, whether they be a student or postgraduate would benefit from studying these chapters' findings as these papers are contextualised well, and are laid out in an engaging and clear manner. Overall, these papers are a useful resource for understanding the various negatives that can occur within social media, whilst also providing potential solutions to those same issues.

\section{Reference List}

Fisher, R.J. (1993) 'Social desirability bias and the validity of indirect questioning', Journal of Consumer Research, 20(2), 303-315.

Mäntymäki, M. and Riemer, K. (2016) 'Enterprise social networking: a knowledge management perspective', International Journal of Information Management, 36(6), 1042-1052.

Nicholas Furze is a Sessional lecturer at Canterbury Christ Church University. He is also currently working on his $\mathrm{PhD}$ which is entitled 'Adapting History: Applying Adaptation Theory to Historical Film and Television', and has presented his research at the annual conferences for the British Association of Film, Television and Screen Studies (2016 and 2017), The Association of Adaptation Studies (2016 and 2017), The Media, Communication and Cultural Studies Association Post-Graduate Network Conference (2018), and at The Game of Thrones Symposium at the University of Hertfordshire (2017).

Email: nicholas.furze@canterbury.ac.uk 